\title{
On the Asymmetry of Wind Distribution in the Lower Layer in Typhoon
}

\author{
By Sadao Yoshizumi* \\ Geophysical Institute and Meteorological Research Institute; Kyoto University, Kyoto \\ (Manuscript received 14 October 1967, in revised from 20 April 1968)
}

\begin{abstract}
The wind field in the lower layer in a moving typhoon of circular concentric isobar pattern is discussed. Effect of storm movement results in higher wind in the right semicircle than in the left, and the effect of surface friction adds front-rear asymmetry to that due to storm movement. Numerical estimation of the wind field in the friction layer of the moving typhoon depicts characteristics of actually observed asymmetry.
\end{abstract}

\section{Introduction}

It is well known that typhoons have such asymmetric wind distribution that the wind is stronger in the right semi-circle than in the left (I. M. Cline [1926]). An asymmetry between the front semi-circle and the rear is also observed, and the maximum speed is actually located in the right rear quardrant in the wind field averaged over many typhoons (L. A. Hughes [1952]). But no comprehensible explanation has yet been given. Many meteorologists have attempted to interprete these asymmetry as the effects of storm movement, following W. Ferrel [1911], but they have no fruitful results. They have not made adequate allowances for non-linearity of equation of motion.

Another meteorologists have attempted to attribute it to asymmetric pressure pattern (T. Namekawa and S. Aoki [1955]) and to kinematics of wind field. (L. Sherman [1956]). About the asymmetric pressure pattern, N. E. LaSeur and H. F. Hawkins [1963] pointed out that asymmetry of observed pressure pattern was too weak to account for that of observed wind pattern by itself. Sherman did not estimate the extent of asymmetry quantitatively.

It is not expected from a viewpoint of isallobaric wind that the wind field in a station-

* Present affiliation: Meteorological Research Institute, Tokyo. ary typhoon is the same as that in a moving typhoon with the same isobar pattern. Th. Hesselberg [1924] has determined the pressure pattern in a moving cyclone which has an axi-symmetric field of surface wind relative to its center. His results suggest that the surface wind field in a moving typhoon may probably have asymmetry to front-rear as well as to right-left, even if its isobar pattern is concentric circular.

V. A. Myers and W. Malkin [1961] recently attempted to estimate the surface wind distribution for a storm with concentric circular isobar pattern which propagates with a constant velocity. They used an empirical expression of frictional force which is assumed to be proportional to the square of total wind speed. Their results derived graphically have some disagreements with the observed distribution of wind (Hughes [1952]), especially in respect of the radial velocity component relative to the earth's surface.

In the present paper, the effect of frictional force on wind field in moving storm will be evaluated by using a method different from Myers and Malkin's one.

\section{Basic equations for determining the wind distribution}

We shall examine the deformation of wind pattern due to storm movement when a storm with concentric circular isobar pattern propagates at a constant speed, as Myers and Malkin did. Now discussions will be confined 
to the wind pattern which remains unchanged during the movement of the storm. Referring to a coordinate system moving with the storm, the equation of motion can be written as follows :

$$
\left(\boldsymbol{V}_{s} \cdot \nabla_{H}\right) \boldsymbol{V}_{s}+f \boldsymbol{k} \times \boldsymbol{V}_{s}=-\frac{1}{\rho} \nabla_{H} p-f \boldsymbol{k} \times \boldsymbol{C}+\boldsymbol{F}
$$

where $V_{s}$ is relative wind or wind vector relative to the storm center, so adding the storm velocity, $\boldsymbol{C}$, to it gives the wind vector seen from the earth, i. e.,

$$
V_{e}=V_{s}+C
$$

Other notations are conventional. It appears that neglect of the vertical advection term is reasonable except in the storm with low speed (cf. S. L. Rosenthal [1961]).

The frictional force, $\boldsymbol{F}$, is assumed to be negligible in the free atmosphere and is taken account into in the boundary layer only, by applying modified Ekman spiral (S. L. Rosenthal [1962]). The assumption of motion will be discussed later.

First, the frictionless flow in the free atmosphere will be evaluated. The equation (1) is, then, reduced to

$$
\left(\boldsymbol{V}_{s} \cdot \boldsymbol{V}_{H}\right) \boldsymbol{V}_{s}+f \boldsymbol{k} \times \boldsymbol{V}_{s}=-\frac{1}{\rho} \nabla_{H} p-f \boldsymbol{k} \times \boldsymbol{C}
$$

Except for the term, $-f \boldsymbol{k} \times \boldsymbol{C}$, the equation (3) has the same form as the equation of motion in steady state in the coordinate system fixed to the earth.

Thus, if the sum of the two terms on the right hand side, $-(1 / \rho) \boldsymbol{D}_{H} p-f \boldsymbol{k} \times \boldsymbol{C}$, which will be called apparent pressure force hereafter, might be treated similarly to the pressure force in so-called gradient wind equation, the equation (3) for $\boldsymbol{V}_{s}$ can be solved in the same way as the equation in the fixed coordinates. Thus the first approximate value of $V_{s}$ may be obtained from

$$
K_{s} V_{s}^{2}+f V_{s}=\frac{1}{\rho} \frac{\partial p}{\partial r} \cos \beta-f C \cos (\theta+\beta)
$$

with the assumption that streamlines of relative motion are everywhere perpendicular to apparent pressure force. Here $\beta$ is an angle between $V_{s}$ and the tangent to isobar, and $K_{s}$ the curvature of relative streamline, respectively. A polar coordinate $(r, \theta)$ with its origin at the storm center is taken where positive $\theta$ is measured counterclockwise. The storm moves in the direction of $\theta=90^{\circ}$.

Since the streamlines are normal to apparent pressure force, we obtain the relationship:

$$
\tan \left(\beta+90^{\circ}\right)=-\frac{\frac{1}{f \rho} \frac{\partial p}{\partial r}+C \cos \theta}{C \sin \theta}
$$

from geometrical consideration. Using the equation (5) and one derived from its differentiation with respect to $\theta$, the curvature of streamline, $K_{s}$, can be expressed in the form :

$$
K_{s}=\frac{1}{r} \cdot \frac{1+A^{2}-2 A \cos \theta+A^{2} B \sin \theta}{\left(1+A^{2}-2 A \cos \theta\right)^{3 / 2}}
$$

where

$$
\begin{array}{llrl}
A & =\frac{C}{(1+K) V_{g r}}, & B & =\frac{(1+2 K)(S-K)}{(1+K) K}, \\
K & =\frac{V_{g r}}{f r}, & S & =\frac{1}{f} \frac{\partial V_{g r}}{\partial r}
\end{array}
$$

Here, $V_{g r}$ denotes the gradient wind corresponding to the concentric circular isobars.

Under the condition that $V_{s}$ must approach to geostrophic wind in the case of $C=0$ and $K_{s}=0$, the equation (4) yields the solution for $V_{s}$ :

$$
\begin{aligned}
& V_{s}= \\
& \frac{f}{K_{s}}\left[\sqrt{\frac{1}{4}+\left\{(1+K) V_{g r} \cos \beta-C \cos (\theta+\beta)\right\} K_{s} / f}\right. \\
& \left.\quad-\frac{1}{2}\right]
\end{aligned}
$$

$\theta$ - and $r$-components are given by

$$
\begin{aligned}
& V_{s \theta}=V_{s} \cos \beta \\
& V_{s r}=-V_{s} \sin \beta
\end{aligned}
$$

respectively. Thus the frictionless flow can be determined approximately by using the equations (6), (7) and (8).

Along $\theta=0^{\circ}$ and $180^{\circ}$, i. e., on the right and the left of storm center, we obtain

$$
\beta=0
$$

from equation (5) and 


$$
K_{s}= \begin{cases}1 / r(1-A) & \text { along } \theta=0^{\circ} \\ 1 / r(1+A) & \text { along } \theta=180^{\circ}\end{cases}
$$

from equation (6). Substituting these values of $\beta$ and $K_{s}$ into equations (7) and (8), equation (8) can be expressed in the vector from

$$
V_{s}=V_{g r}-\frac{C}{1+K}
$$

Adding $\boldsymbol{C}$ to $\boldsymbol{V}_{s}$ given by the equation (9), we obtain the wind velocty relative to the earth's surface along the line $\theta=0^{\circ}$ and $180^{\circ}$ :

$$
\boldsymbol{V}_{e}=\boldsymbol{V}_{g r}+\frac{K}{1+K} \boldsymbol{C}
$$

It follows from the equation (10) that the second term on the right hand side of the equation presents the difference of wind distribution between the right and the left of storm center. $K$ in typhoon is usually much larger than unity near the center and decreases with raidal distance. Since the vector $K /(1+$ $K) \cdot C$ is parallel to storm movement, this results in asymmetry of wind velocity component along the movement direction. And its asymmetry decreases with radial distance, because its fraction to movement speed, $K$ / $(1+K)$, decreases with the distance from the center, where it is nearly equal to unity. This has already been inferred from the equation (3) by K. Takahashi [1944].

A next step is to take account of the surface friction. The approximate solution in the modified Ekman spiral by Rosenthal [1962] will be used, which is derived from linearized equation for steady, axi-symmetrical flow. The solution can be written in the form:

$$
\left.\begin{array}{l}
v_{\theta}=V_{g r}+V^{\prime} \exp (-b z) \cos (\alpha-b z) \\
v_{r}=-\sqrt{\frac{1+2 K}{1+K+S}} V^{\prime} \exp (-b z) \sin (\alpha-b z)
\end{array}\right\}
$$

where

$$
b=\left\{(1+2 K)(1+K+S) / 4 f K_{m}\right\}^{1 / 4}
$$

Here $K_{m}$ is kinematic coefficient of eddy viscosity. $V^{\prime}$ is an integration constant to be determined, together with $\alpha$, from the boundary condition at the surface.

In order to apply the equation (11) to the present problem, cylindrical coordinates $\left(r^{\prime}\right.$, $\left.\theta^{\prime}, z^{\prime}\right)$ that are moving with the storm are adopted and set at each computation point in such way that $\theta^{\prime}$-direction is coincident with the direction of frictionless flow and that the distance to the origin is equal to the reciprocal of $K_{s}$. Since the earth's surface moves with velocity, $-\boldsymbol{C}$ in the moving coordinate, the lower boundary condition that shearing stress at the surface balances with the drag force of the earth's surface is :

$$
\left.\rho K_{m} \frac{\partial v}{\partial z^{\prime}}\right|_{z^{\prime}=0}=\rho C_{d}\left|v_{0}+C\right| \cdot\left(r_{0}+C\right)
$$

where $C_{d}$ is the drag coefficiect. The subscript zero indicates the value at the surface. Using the equations (11) and (12), we obtain the following relationships for $\alpha$ and $V^{\prime}$ :

$$
\begin{gathered}
\tan \alpha=-b /\left\{b+\left|\boldsymbol{v}_{0}+C\right| \cdot \frac{C_{d}}{K_{m}}\right\} \\
V^{\prime}=-\left(V_{\left.g_{r}+C_{\theta^{\prime}}\right)(\sin \alpha+\cos \alpha)}\right. \\
+\sqrt{\frac{1+K+S}{1+2 K}} C_{r^{\prime}}(\sin \alpha-\cos \alpha)
\end{gathered}
$$

In the equations (11)-(14), $V_{g r}$ must be replaced with the speed of frictionless flow, $V_{s}$ and $K$ and $S$ be calculated for $V_{s}$. Noting also that $\theta^{\prime}$-direction in the above coordinates forms an angle of $\beta$ with that in the original polar ones, $v_{\theta^{\prime}}$ and $v_{r^{\prime}}$ are transformed into $v_{s \theta}$ and $v_{s r}$ through the relation:

$$
\begin{aligned}
& v_{s \theta}=v_{\theta^{\prime}} \cos \beta+v_{r^{\prime}} \sin \beta \\
& v_{s r}=-v_{\theta^{\prime}} \sin \beta+v_{r^{\prime}} \cos \beta
\end{aligned}
$$

Finally, adding $C_{\theta}$ and $C_{r}$ to $v_{s \theta}$ and $v_{s r}$ respectively, we obtain the wind relative to the earth's surface in the lower layer in a moving typhoon.

\section{Numerical results}

Numerical calculations of the wind distribution are made for a moving model typhoon with such an isobar pattern that the corresponding gradient wind speeds, $V_{g r}$, are given by

$$
V_{g r}=\frac{2 V_{\max } r / r_{0}}{1+\left(r / r_{0}\right)^{2}}
$$

where $r$ is a distance from its center. $V_{g r}$ reaches the maximum value, $V_{\max }$, at $r=r_{0}$ 
$\left(=50 \times 10^{3} \mathrm{~m}\right)$ which is taken as $50 \mathrm{~m} / \mathrm{sec}$. Other constants which are necessary for this calculation are chosen as follows:

$$
\begin{aligned}
C & =10 \mathrm{~m} \mathrm{sec}^{-1} \\
f & =0.8 \times 10^{-4} \mathrm{sec}^{-1} \text { (about } 31 \text { deg. lat. N) } \\
C_{d} & =3 \times 10^{-3} \\
K_{m} & =10^{2} \mathrm{~m}^{2} \mathrm{sec}^{-1}
\end{aligned}
$$

The numerical results with these values are shown in Figs. 1-7.

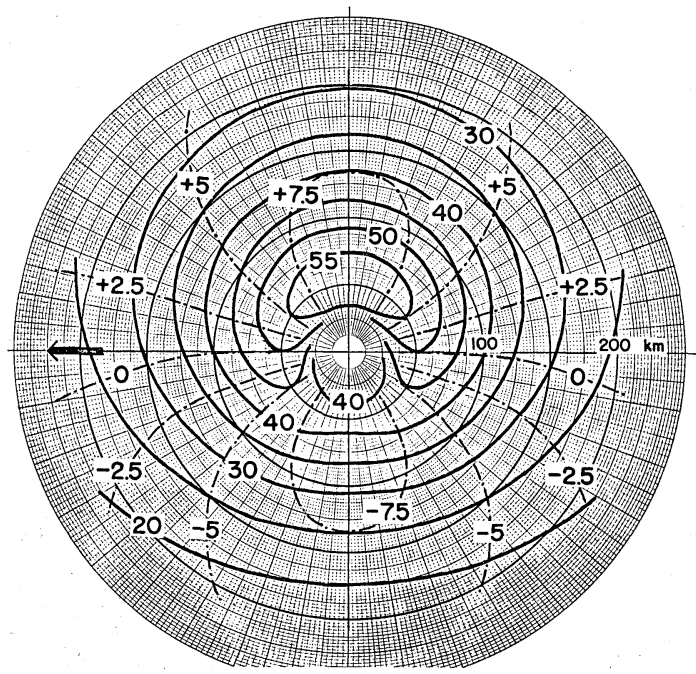

Fig. 1. Tangential component of frictionless flow (full line) and its difference between a moving storm and a stationary one (dotdash line). Arrow indicates the direction of the storm movement. Unit is $\mathrm{m} \mathrm{sec}^{-1}$.

Fig. 1 shows the distribution of the tangential component of frictionless flow above the boundary layer. This tangential speed, as expected from the equation (10), is higher in the right semi-circle than in the maximum difference is about $19 \mathrm{~m} / \mathrm{sec}$, slightly less than twice the storm speed. This fact can also be seen from the distribution of the difference of tangential component between the moving storm and the stationary one shown by dotdash lines in Fig. 1, which is given by subtracting the gradient wind (16) from the tangential velocity shown by full lines in the same figure. This figure also shows that the effect of the storm movement is symmetrical between the front and the rear semi-circles.

Computed radial component of frictionless flow, shown in Fig. 2, is anti-symmetric in

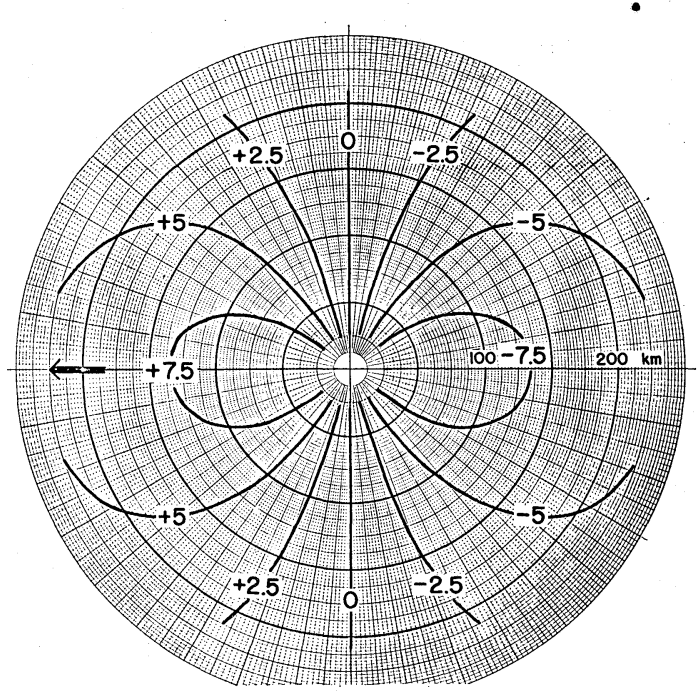

Fig. 2. Radial component of frictionless flow. Positive values indicate outflow and negative inflow. Unit is the same as Fig. 1.

such a way that outflow found in the front semi-circle and inflow in the rear. This component has the maximum value of about $9.5 \mathrm{~m} / \mathrm{sec}$ just near the center and decreases in intensity with increasing radial distance. This means that the frictionless wind velocity relative to the storm center has inward component in the front and outward one in the rear.

We shall compare the computed patterns of frictionless flow show in Figs. 1 and 2 with those observed at middle levels in tropical storms [E. S. Jordan (1952), B. I. Miller (1958]). The distributions of the both computed components, tangential and radial, are quite similar to the observed ones, though these distributions are different from each other in scale. The right-left difference of speed in Miller's analysis smaller than twice the storm speed, while that in Jordan's one is larger. At least in this point the computed result is rather closer to the observational result by Miller (1958) which was obtained from larger amount of data than that by Jordan (1952).

Concerning the maximum difference between the tangential speeds at any point in the right and at the correspoinding distance in the left, Gray (1962) reported the several examples where the difference was greater than twice the movement speed of storm. This leads us to doubt assumptions of fric- 
tionless motion and hence of steamlines normal to the apparent pressure force, even in the middle troposphere. In fact, he considers that a main cause of the wind asymmetry may be small-scale fluctuations of wind associated with cumulus convection. These wind fluctuations give rise to internal stresses on larger-scale circulation around tropical cyclone, which were attempted to estimate from wind observations by Gray (1966). But the relation of such internal stresses to larger-scale motion has not well understood. Moreover, cumulus convective activity is found to be rather variable in time and space [R. C. Gentry (1964)]. Incorporation of this friction is an important problem to solve in future.

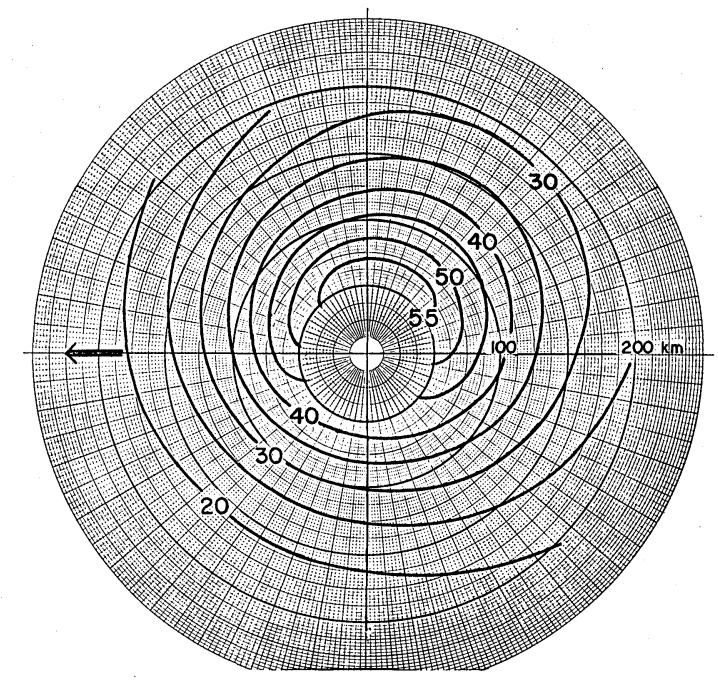

Fig. 3. Total wind speed at the height of 0.3 $\mathrm{km}$. Unit is the same as Fig. 1.

The wind distributions at the surface and the height of $0.3 \mathrm{~km}$ were calculated with the equations (11) that satisfy the lower boundary condition (12) and the upper one of the approach to the frictionless flow at an infinite height. It is noted in Fig. 3 that computed total wind speed at $0.3 \mathrm{~km}$ has not only rightleft asymmetry but also front-rear one. The backward shift of the strongest wind region, though not so far as in Hughes's (1952) result, is revealed more clearly in Fig. 4 which shows the difference of the total wind speed from that in the case of the stationary storm $(C=$ $0)$. The computed total wind speed at the surface is shown in Fig. 5 and it can be

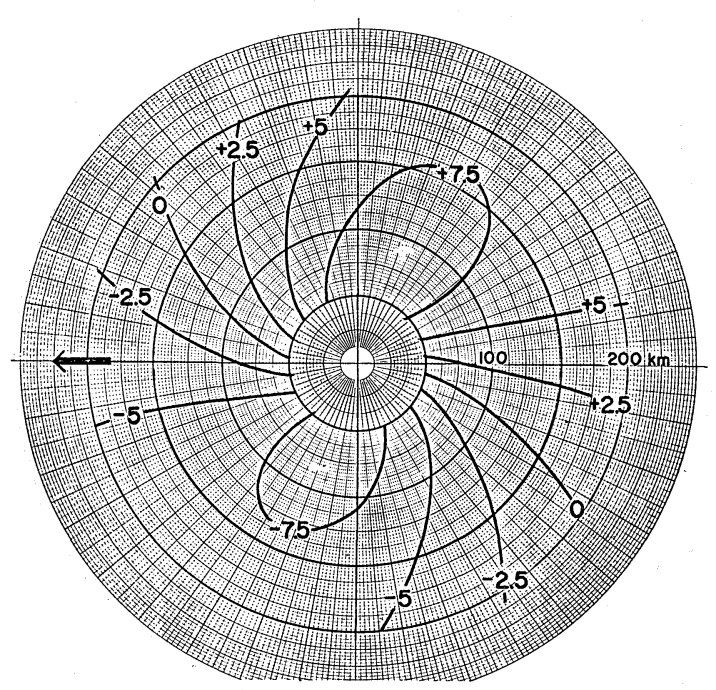

Fig. 4. Difference of total wind speed between a moving storm and a stationary one at the height of $0.3 \mathrm{~km}$. Unit is the same as Fig. 1.

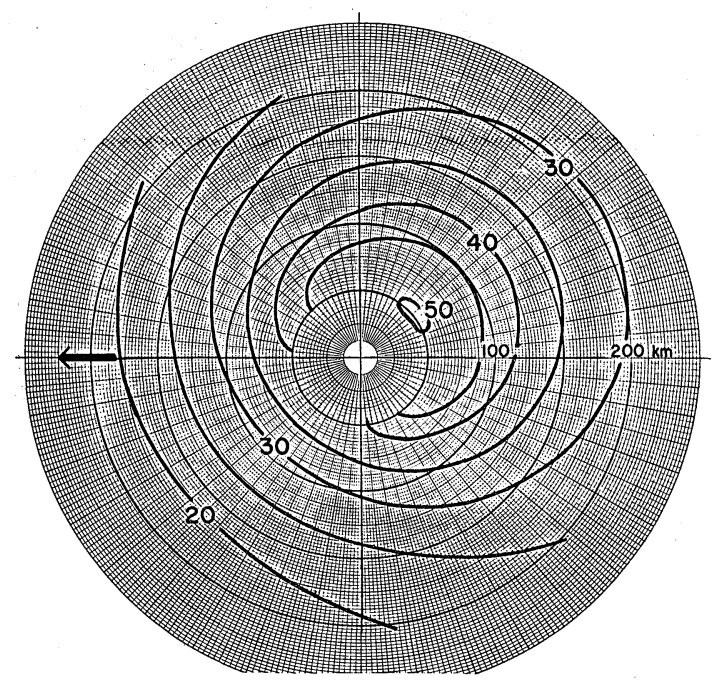

Fig. 5. Total wind speed at the earth's surface. Unit is the same as Fig. 1.

readily seen that the strongest wind region shifts backward to the same extent as that in Hughes's figure. At the height of $0.3 \mathrm{~km}$ and the surface, the maximum difference of wind speed along any circle centered at the storm center has the greatest value of about $19 \mathrm{~m} / \mathrm{sec}$ at $r=50 \mathrm{~km}$, i. e., the radius of the maximum wind speed.

The tangential velocity component is not appreciably different from the total velocity, 


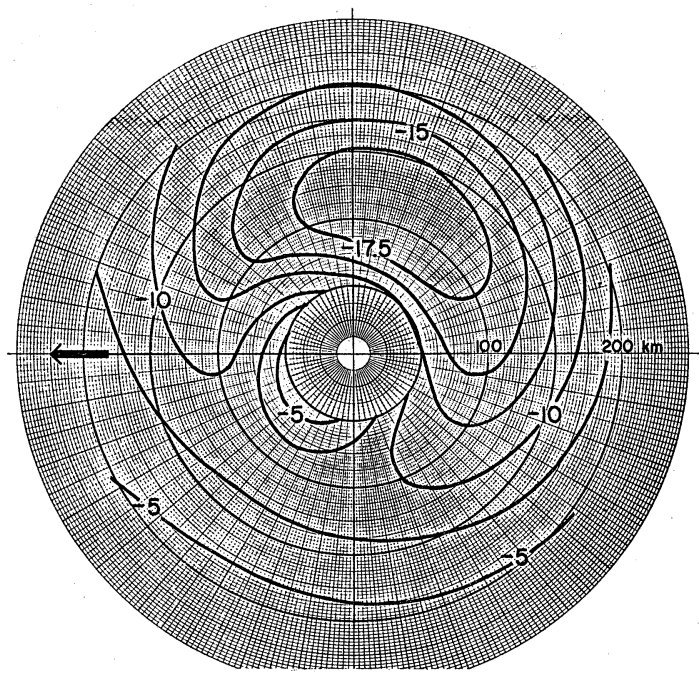

Fig, 6. Radial velocity component at the height of $0.3 \mathrm{~km}$. Unit and sense are the same as Fig. 2 .

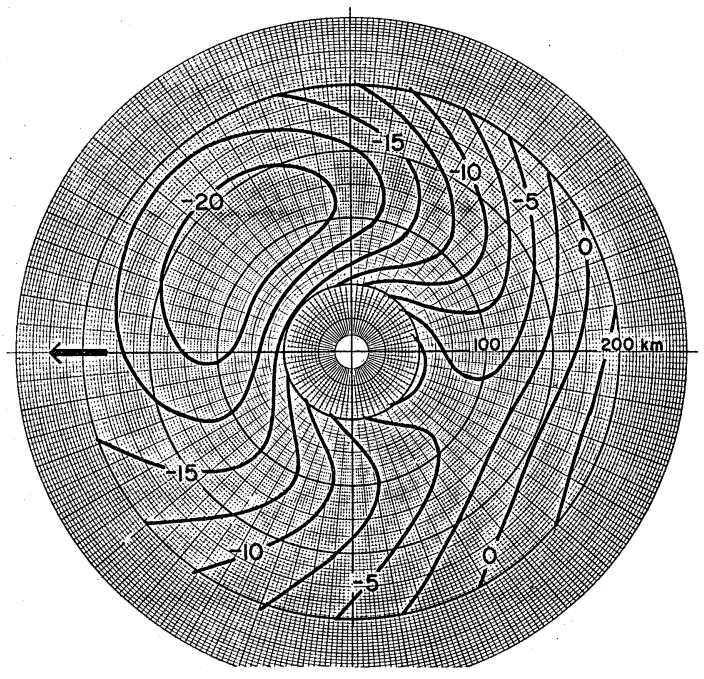

Fig. 7. Radial velocity component relative to the storm center at the height of $0.3 \mathrm{~km}$. Unit and sense are the same as Fig. 2.

so the description of the former will not be given here.

At the height of $0.3 \mathrm{~km}$ the computed radial velocity is negative, i. e., inward in all the area for which the computation was made (Fig. 6). The region of maximum inflow is located in the right-rear quadrant and the inflow component is smaller in the left-front than any other quadrants. In the distribution of the radial component relative to the storm center (Fig. 7), maximum inflow occurs in the right-front and its value is roughly equal to that of the radial component relative to the earth's surface. These results are in agreement with observational studies [Hughes (1952), Miller (1958)]. The outflow near the center in each radial component, was depicted in Figs. 6a and 7a of Miller's report, while it cannot be found in Figs. 6 and 7 of the present paper. This discrepancy may probably be due to the fact that the distributions presented by Miller (1958) are those averaged through the $0-1 \mathrm{~km}$ layer. The inflow in the boundary layer is weaker in the left-front than in any other quadrants, and the frictionless motion above the layer has outward component in the front semi-circle. Thus, the flow pattern averaged through the $0-1 \mathrm{~km}$ layer may be expected to have an outflow in the left-front quadrant. If "front" is replaced with "rear", the same reasoning holds for the radial component relative to the storm center. Similarly, asymmetry of the tangential speed between the front and rear semicircles may rather weaker in the pattern averaged through the $0-1 \mathrm{~km}$ layer by Miller (1958).

\section{Concluding remarks}

It was shown that one can derive nearly similar features to those of the actual wind field in the lower layer in typhoons, by considering the storm movement and the effect of friction. The former causes the wind field to be asymmetric in respect to the direction of storm movement, and the latter to front-rear. But the fact that the asymmetry of the computed wind field in the free atmosphere is often weaker than the observed one requires more investigations, particularly about the roles of cumulus convection and others.

\section{Acknowlegdements}

The author wishes to express his sincere thanks to Prof. R. Yamamoto and to Dr. Y. Mitsuta of Disaster Prevention Research Institute, Kyoto University, for their guidance and encouragement throughout the present study.

\section{References}

Cline, I. M., 1926: Tropical cyclone. MacMillan 
Co., New York. 301 pp.

Ferrel, W., 1911: A popular treatise on the winds, 2nd ed. John Willy \& Sons, New York. 505 pp.

Gentry, R. C., 1964: A study of hurricane rain bands. NHRP Report No. 69.85 pp.

Gray, W. M., 1962: On the balance of forces and radial accelerations in hurricanes. Quart. J. Roy. meteor. Soc., 88, 43J-458.

$\longrightarrow, 1966$ : On the scales of motion and internal stress characteristics of the hurricane. J. atmos. Sci., 23, 278-288.

Hesselberg, Th., 1924: Mögliche Luftbewegungen an der Erdoberfläche. Geofys. Publ., 3(7). 22 $\mathrm{pp}$.

Hughes, L. H., 1952: On the low-level wind structure of tropical storms. J. Meteor., 9, 422-428.

Jordan, E. S., 1952: An observational study of the upper wind circulation. J. Meteor., 9, 340-346.

LaSeur, N.E. and H.F. Hawbins, 1963: An analysis of Hurricane Cleo (1958) based on data from research reconnaissance aircraft. Mon. Wea. Rev., 91, 694-709.
Miller, B. I., 1958: The three dimensional wind structure around a tropical cyclone. NHRP Report No. 15. 41 pp.

Myers, V. A. and W. Malkin, 1961: Some properties of hurricane wind field as deduced from trajectories. NHRP Report No. $49.45 \mathrm{pp}$.

Namekawa, T. and S. Aoki, 1955: On the structure of the disastrous typhoon hitting the Japanese Islands. Proc. UNESCO Symposium of Typhoons, 55-77.

Rosenthal, S. L., 1961: Concerning the mechanics and thermodynamics of the inflow layer of the mature hurricane. NHRP Report No, 47., 31 pp.

, S. L., 1962: A theoretical analysis of the field of motion in the hurricane boundary layer. NHRP Report No. $56.12 \mathrm{pp}$.

Sherman, L., 1956: On the wind asymmetry of hurricanes. J. Meteor., 13, 500-503.

Takahashi, K., 1944: On the wind in the traveling pressure field. J. meteor. Soc. Japan, 22, 19-22. (in Japanese)

\title{
台風域内の風速分布の非対称性について
}

\author{
吉 住 禎夫 \\ (京都大学理学部)
}

気圧分布が同心円状である台風が一定速度 $\boldsymbol{C}$ で移動している時の下層に抢ける風速分布を論ずる。座標系は, 台 風ととすと移動する座標系を採用する。

まず, 摩擦を無視し, 相対流線が $-\nabla_{H} p-f \boldsymbol{k} \times \boldsymbol{C}$ 亿垂直であると仮定して, 傾度風近似により移動のみの影響を 調べる。次に, 地表摩擦を考慮するために, 初め飞求めた風速分布を境界層上の風とし; Rosenthal (1962) の modified Ekman spiral を適用して, 台風域内の下層の風速分布を求める。

その結果，移動とより左右の非対称性は生ずるが，前後の非対称性は生じない。地表薬擦を考虑することとより， 最強風域が右後方に, 動径分值飞ついては inflow の最大が右後方に, 中心飞相対的な動径分值飞ついては, inflow の最大が右前方飞得られ，実測されるような風速分布の非対称性が説明される。 